\title{
A prospective assessment of antimicrobial agents utilization pattern in a tertiary care hospital
}

\author{
Sartaj Hussain ${ }^{1}$, Kamal K. Sawlani' ${ }^{2}$, Suraj S. Yadav ${ }^{1}$, Sanjay Khattri ${ }^{1 *}$
}

\begin{abstract}
${ }^{1}$ Department of Pharmacology,
${ }^{2}$ Department of Medicine, King George's Medical University, Lucknow, Uttar Pradesh, India
\end{abstract}

Received: 29 October 2016 Accepted: 29 November 2016

*Correspondence to:

Dr. Sanjay Khattri,

Email:

drsanjaykhattri@gmail.com

Copyright: () the author(s), publisher and licensee Medip Academy. This is an openaccess article distributed under the terms of the Creative Commons Attribution NonCommercial License, which permits unrestricted noncommercial use, distribution, and reproduction in any medium, provided the original work is properly cited.

\begin{abstract}
Background: The antimicrobial resistance is increasing globally and, concurrently, downward trend in development of newer antibiotics is leading to a serious public health problem and economic consequences.

Methods: Prescriptions with at least one antimicrobial were included in the study. A total of 242 prescriptions were included in the study. The antimicrobials were classified into different classes based on WHO-ATC classification.

Results: A total of 281 antimicrobials prescribed in 242 prescriptions with an average of 1.16 per prescription. In most of the prescriptions, 1 antimicrobial were prescribed $(88.43 \%)$. The routes of the antimicrobial administration were mostly oral $268(95.37 \%)$ followed by injectable $13(4.63 \%)$. The most commonly prescribed classes of antimicrobial in this study were antibacterials for systemic use (J01) (74.02\%) followed by antimycobacterials (J04) (13.88\%), antiparasitic drugs (P) (8.19\%), antimycotics for systemic use (J02) (2.49\%) and antivirals for systemic use (J05) (1.42\%). Among antibacterials, the most commonly prescribed classes of antibacterial was various antibacterial FDCs $(19.22 \%)$, followed by quinolones $(18.86 \%)$, macrolides $(18.15 \%)$, $\beta$-lactams $(11.03 \%)$ cephalosporins $(6.76 \%)$, penicillins $(4.27 \%)$, aminoglycosides $(2.84 \%)$, metronidazole $(1.78 \%)$, clindamycin $(1.78 \%)$ and tetracycline $(0.36 \%)$. The total percentage of antimicrobials prescribed as Fixed Dose Combinations (FDCs) were $32.38 \%$.

Conclusions: The present study has reported that most commonly prescribed antimicrobials were quinolones followed by macrolides and $\beta$-lactams. Recommendations to change the ongoing prescribing practices should be based on the Standard Treatment Guidelines, EDL and Antibiotic policy or by following the information, education, and communication (IEC) interventions.
\end{abstract}

Keywords: Antimicrobial utilization pattern, Anatomical Therapeutic and Chemical - ATC, Essential Drug List- EDL, World Health Organization - WHO

\section{INTRODUCTION}

Drug utilization is defined by the World Health Organization (WHO) as "the marketing, distribution, prescription, and use of drugs in society, with special emphasis on the resulting medical, social, and economic consequences". ${ }^{1}$ Overall, $80-90 \%$ of the antibiotics are consumed in outpatients and the rest in inpatients. ${ }^{2}$ About $20-50 \%$ of all antibiotic use is irrational and this irrational use leads to increased risk of adverse drug events, increase in antimicrobial resistance and higher health care cost. ${ }^{3,4}$ In the outpatients, the antibiotics are most commonly prescribed for fever, sore throat and diarrhea. These infections are usually viral in origin and antimicrobials have no role in their treatment. ${ }^{5}$

The 'microbial threat' was first recognized as a widespread problem in the 1990s and is now highlighted as a major global risk by several agencies, including the World Health Organization (WHO) and World Economic Forum (WEF). ${ }^{6-8}$ The antimicrobial resistance is increasing globally and, concurrently, downward trend in development of newer antibiotics are leading to serious public health problem and economic consequences. There are many factors responsible for antimicrobial resistance, but the utmost important is the overall quantity of antimicrobial consumption., ${ }^{2,3}$ Between 2000 and 2010, 
the worldwide antibiotic consumption increased by $36 \%$ and $76 \%$ of which was in Brazil, Russia, India, China, and South Africa. In 2010, India was the single largest consumers of antibiotics in the world, followed by China and US. ${ }^{10}$

Antibiotic resistance is a major determinant of the outcome of infectious disease management. The clinician is not only important to development of this issue but also key to control it. ${ }^{11}$ The prescribing practice of clinician is affected by various elements and to modify this it is essential to understand reason behind it. ${ }^{12}$ It is utterly important to assess and audit the antimicrobials utilization pattern periodically for enabling suitable modifications in utilization patterns; to increase the therapeutic benefits and also to decrease the health care cost, antimicrobial resistance, adverse drug events for improving the medical services. ${ }^{13}$

The aim of this study was to assess the utilization pattern of different classes of antimicrobials in the Medicine OPD of a tertiary care teaching hospital along with the study of the dosage form of antimicrobials. We also assessed the utilization of antimicrobials from the essential drug list and as fixed dose combinations.

\section{METHODS}

Institutional Ethical Committee permission was taken before the start of the study.

\section{Study site}

This study was conducted in the Out Patient Department of General Medicine, King George's Medical University, Lucknow, India.

\section{Study period}

This study was carried out prospectively over a period of 1 month, from $1^{\text {st }}$ January 2016 to $31^{\text {st }}$ January 2016.

It was a prospectively designed cross-sectional observational study.

\section{Sample size}

Total 1000 patients of either sex, visiting for the first time to the OPD were selected randomly for the study. Prescriptions with at least one antimicrobial were included in the study. Those constituted 242 out of 1000 prescriptions screened.

\section{Patient selection}

\section{Inclusion criteria}

Patient attends medicine OPD and were ready to give consent were included in the study. Prescription containing at least one antimicrobial agent.

\section{Exclusion criteria}

Patient who was followed up, referral patients, seriously ill patients and mentally disabled patients.

\section{Study material}

Proforma was designed for recording patient's specific information such as patient's demographic profile, diagnosis, drug, name, dose, route, frequency and duration of prescription. The antimicrobials were classified into different classes based on WHO-ATC classification. The brand name of drugs was decoded by CIMS drug manual for the purpose of analysis.

\section{Prescribing indicators}

a. Percentage of encounters with an antimicrobial

b. Percentage of antimicrobial prescribed in fixed dose combination (FDCs)

c. Percentage of antimicrobial drug prescribed from the Essential Drug List.

\section{Statistical analysis}

Statistical Packages for Social Sciences (SPSS) version 20 was used for entry and analysis of the quantitative data. In the statistical analysis, frequencies, averages/means, and percentages were obtained.

\section{RESULTS}

\section{Demographic data}

Out of 1000 prescriptions, only 242 prescriptions had at least one antimicrobial and were selected for analysis. The percentage of males was $54.96 \%$ and that of females was $45.04 \%$. Age distribution shows, most of the patients were adults (20-60 years) constituting $81.82 \%$, followed by adolescents (15-19 years) $9.50 \%$ and geriatric $(\geq 60$ years) $8.68 \%$ (Table 1 ).

Table 1: Baseline demographics of the patients.

\begin{tabular}{|ll|}
\hline Age & No. $(\%)$ \\
\hline Adolescents (15-19 year) & $23(9.50 \%)$ \\
\hline Adults (20-60 year) & $198(81.82 \%)$ \\
\hline Geriatric (>60 year) & $21(8.68 \%)$ \\
\hline Gender & No. $(\%)$ \\
\hline Male & $133(54.96 \%)$ \\
\hline Female & $109(45.04 \%)$ \\
\hline
\end{tabular}

\section{Prescription data}

A total of 281 antimicrobials prescribed in 242 prescriptions with an average of 1.16 per prescription. In most of the prescriptions, 1 antimicrobial were prescribed $(88.43 \%)$, followed by 2 antimicrobial $(8.26 \%), 3$ 
antimicrobial $(2.07 \%)$, and 4 antimicrobial in $1.24 \%$ of prescriptions (Table 2).

Table 2: Number of antimicrobials prescribed per prescription.

\begin{tabular}{|ll|}
\hline No. of antimicrobials & No. of prescriptions (\%) \\
\hline 1 & $214(88.43 \%)$ \\
\hline 2 & $20(8.26 \%)$ \\
\hline 3 & $5(2.07 \%)$ \\
\hline 4 & $3(1.24 \%)$ \\
\hline Total & $242(100 \%)$ \\
\hline
\end{tabular}

Routes of antimicrobial administration were mostly oral $268(95.37 \%)$ followed by injectable $13(4.63 \%)$. The most common antimicrobial prescribed in injectable was streptomycin (8), followed by benzathine benzylpenicillin (4) and Cefoperazone+Sulbactam (1).

The most commonly prescribed classes of antimicrobial in this study were antibacterials for systemic use (J01) (74.02\%) followed by antimycobacterials (J04) (13.88\%), antiparasitic drugs (P) $(8.19 \%)$, antimycotics for systemic use (J02) (2.49\%) and antivirals for systemic use (J05) (1.42\%) (Table 3).
The total percentage of antimicrobials prescribed as Fixed Dose Combinations (FDCs) were $32.38 \%$. The antimicrobial FDCs mostly were antibacterials (19.22\%) followed by antimycobacterials (9.25\%), anthelmintics $(4.63 \%)$ and antiprotozoals $(3.56 \%)$ (Table 3$)$.

Table 3: Percentage of different class of antimicrobials as per ATC classification.

\begin{tabular}{|lcll|}
\hline $\begin{array}{l}\text { Class of } \\
\text { antimicrobials }\end{array}$ & $\begin{array}{l}\text { ATC } \\
\text { code }\end{array}$ & $\begin{array}{l}\text { Number } \\
(\%)\end{array}$ & $\begin{array}{l}\text { No. of } \\
\text { FDCs (\%) }\end{array}$ \\
\hline $\begin{array}{l}\text { Antibacterials for } \\
\text { systemic use }\end{array}$ & $\mathrm{J} 01$ & $\begin{array}{l}208 \\
(74.02 \%)\end{array}$ & $\begin{array}{l}54 \\
(19.22 \%)\end{array}$ \\
\hline $\begin{array}{l}\text { Antimycotics for } \\
\text { systemic use }\end{array}$ & $\mathrm{J} 02$ & $7(2.49 \%)$ & $0(0 \%)$ \\
\hline Antimycobacterials & $\mathrm{J} 04$ & $\begin{array}{l}39 \\
(13.88 \%)\end{array}$ & $\begin{array}{l}26 \\
(9.25 \%)\end{array}$ \\
\hline $\begin{array}{l}\text { Antivirals for } \\
\text { systemic use }\end{array}$ & $\mathrm{J} 05$ & $4(1.42 \%)$ & $0(0 \%)$ \\
\hline $\begin{array}{l}\text { Antiprotozoals } \\
\text { P01 }\end{array}$ & $\begin{array}{l}10 \\
(3.56 \%)\end{array}$ & $6(2.13 \%)$ \\
\hline Anthelmintics & $\mathrm{P} 02$ & $\begin{array}{l}13 \\
(4.63 \%)\end{array}$ & $5(1.78 \%)$ \\
\hline Total & & $\begin{array}{l}281 \\
(100 \%)\end{array}$ & $\begin{array}{l}91 \\
(32.38 \%)\end{array}$ \\
\hline
\end{tabular}

Table 4: Percentage of different class of antimicrobials.

\begin{tabular}{|c|c|c|c|}
\hline Class of Antimicrobial & Name of the Antimicrobial & ATC Code & Number $(\%)$ \\
\hline Tetracyclines (J01A) & Tetracycline & J01AA07 & $1(0.36 \%)$ \\
\hline \multirow{3}{*}{ Penicillins (J01C) } & Amoxicillin & J01CA04 & $7(2.49 \%)$ \\
\hline & Ampicillin & J01CA01 & $1(0.36 \%)$ \\
\hline & Benzathine benzylpenicillin & J01CE08 & $4(1.42 \%)$ \\
\hline \multirow{3}{*}{ Cephalosporins (J01D) } & Cefuroxime & J01DC02 & $10(3.56 \%)$ \\
\hline & Cefixime & J01DD08 & $6(2.13 \%)$ \\
\hline & Cefpodoxime & J01DD13 & $3(1.07 \%)$ \\
\hline \multirow{2}{*}{ Macrolides (J01FA) } & Erythromycin & J01FA01 & $7(2.49 \%)$ \\
\hline & Azithromycin & J01FA10 & $44(15.66 \%)$ \\
\hline Lincosamides (J01FF) & Clindamycin & J01FF01 & $5(1.78 \%)$ \\
\hline \multirow{4}{*}{ Quinolones (J01M) } & Ofloxacin & J01MA01 & $28(9.96 \%)$ \\
\hline & Ciprofloxacin & J01MA02 & $7(2.49 \%)$ \\
\hline & Norfloxacin & J01MA06 & $15(5.34 \%)$ \\
\hline & Levofloxacin & J01MA12 & $3(1.07 \%)$ \\
\hline Aminoglycosides (J01G) & Streptomycin & J01GA01 & $8(2.84 \%)$ \\
\hline Other antimicrobials (J01X) & Metronidazole & J01XD01 & $5(1.78 \%)$ \\
\hline Antimycotics for systemic use (J02) & Fluconazole & J02AC01 & $7(2.49 \%)$ \\
\hline \multirow{3}{*}{ Antimycobacterials (J04) } & Rifampicin & J04AB02 & $3(1.07 \%)$ \\
\hline & Isoniazid & J04AC01 & $3(1.07 \%)$ \\
\hline & Pyrazinamide & J04AK01 & $7(2.49 \%)$ \\
\hline Antivirals for systemic use (J05) & Aciclovir & J05AB01 & $4(1.42 \%)$ \\
\hline Antiprotozoals (P01) & Chloroquine & P01BA01 & $4(1.42 \%)$ \\
\hline \multirow{2}{*}{ Anthelmintics (P02) } & Albendazole & P02CA03 & $6(2.14 \%)$ \\
\hline & Ivermectin & $\mathrm{P} 02 \mathrm{CF} 01$ & $2(0.71 \%)$ \\
\hline Various antimicrobial FDCs & & & $91(32.38 \%)$ \\
\hline Total & & & $281(100 \%)$ \\
\hline
\end{tabular}


Among antibacterials, the most commonly prescribed classes of antibacterial was various antibacterial FDCs $(19.22 \%)$, followed by quinolones $(18.86 \%)$, macrolides (18.15\%), $\beta$-lactams (11.03\%) cephalosporins (6.76\%), penicillins $(4.27 \%)$, aminoglycosides $(2.84 \%)$, metronidazole $(1.78 \%)$, clindamycin $(1.78 \%)$ and tetracycline $(0.36 \%)$ (Table 4$)$.

Among the antibacterial FDCs, the most commonly prescribed FDCs were combination of macrolide and cephalosporin $(6.05 \%)$ followed by fluroquinolone and nitroimidazole $(4.63 \%)$, penicillin with $\beta$-lactamase inhibitor $(3.91 \%)$, cephalosporin with $\beta$-lactamase inhibitor $(3.20 \%)$, fluroquinolone and macrolide $(0.71 \%)$, fluroquinolone and cephalosporin and sulfamethoxazoletrimethoprim $(0.36 \%)$ (Table 5).

Table 5: FDCs of different class of antimicrobials.

\begin{tabular}{|ll|}
\hline Name of FDCs & Number $(\%)$ \\
\hline Amoxicillin+Clavulanate & $8(2.85 \%)$ \\
\hline Amoxicillin+Dicloxacillin & $3(1.07 \%)$ \\
\hline Cefixime+Clavulanate & $5(1.78 \%)$ \\
\hline Cefpodoxime+Clavulanate & $3(1.07 \%)$ \\
\hline Cefoperazone+Sulbactam & $1(0.36 \%)$ \\
\hline Macrolide+Cephalosporins & $17(6.05 \%)$ \\
\hline Fluroquinolones+Macrolide & $2(0.71 \%)$ \\
\hline Fluroquinolones+ Cephalosporins & $1(0.36 \%)$ \\
\hline $\begin{array}{l}\text { Fluroquinolones+ Ornidazole/ } \\
\text { Tinidazole }\end{array}$ & $13(4.63 \%)$ \\
\hline Sulfamethoxazole+ Trimethoprim & $1(0.36 \%)$ \\
\hline Isoniazid+Rifampicin & $8(2.85 \%)$ \\
\hline Isoniazid+Rifampicin+Ethambutol & $11(3.91 \%)$ \\
\hline Isoniazid+Pyridoxine & $7(2.49 \%)$ \\
\hline $\begin{array}{l}\text { Artesunate+Sulfadoxine- } \\
\text { Pyrimethamine }\end{array}$ & $3(1.07 \%)$ \\
\hline Artesunate+Lumefantrine & $3(1.07 \%)$ \\
\hline Ivermectin+Albendazole & $5(1.78 \%)$ \\
\hline Total & $91(32.38 \%)$ \\
\hline
\end{tabular}

The antimicrobials prescribed from the National Essential Drugs List were $47.68 \%$.

\section{DISCUSSION}

Assessment of the antimicrobial prescription is an important issue because of rapidly increasing antimicrobial resistance across the globe, lack of adherence to standard treatment guidelines and increase in health care expenditure.

The average number of drugs per prescription is an important index of prescription audit. Polypharmacy is usually associated with negative consequences such as increased chances of drug interactions, adverse drug events, medication non-adherence and ultimately increased health care cost. In this study, a total of 281 antimicrobials prescribed in 242 prescriptions with an average of 1.16 . In a study conducted by Khan et al it was $1.61 .^{14}$

The average number of antimicrobials per prescription was mostly one $(88.43 \%)$ followed by two antimicrobials in $8.26 \%$ prescriptions. The FDCs constituted $32.38 \%$ of total antimicrobials. Two studies from India reported antimicrobial FDCs as $18.88 \%$ and $29.18 \%$, respectively. ${ }^{15,16}$

In the present study, most commonly prescribed antimicrobial class was quinolones followed by macrolides, $\beta$-lactams, and aminoglycosides. In the study conducted by Admane et al, most commonly prescribed antimicrobials were $\beta$-lactam antibiotics (61.54\%) followed by sulphonamides (26.05\%) and fluoroquinolones (6.97\%). ${ }^{16}$ Another study by Selvaraj et al, reported $\beta$-lactams (35.09\%), followed by fluoroquinolones $(18.88 \%)$ and combinations of antimicrobials from different classes $(13.85 \%)$ as the most commonly prescribed classes of antimicrobials. ${ }^{15}$ Lalan et al, reported that the most commonly prescribed antimicrobials were Ciprofloxacin $(3.80 \%)$, followed by Amoxicillin (3.73\%) and Metronidazole (2.30\%). ${ }^{17}$ According to Khan et al, most commonly prescribed antimicrobials were the $\beta$-lactams (penicillins and cephalosporins) followed by the quinolones, Nitroimidazoles , aminoglycosides and the macrolides. ${ }^{14}$

Among different classes of antimicrobial FDCs, the combination of macrolide and cephalosporin was the most frequently prescribed combination followed by combination of fluroquinolone and nitroimidazole and combination of penicillin with $\beta$-lactamase inhibitor.

The percentage of antimicrobials prescribed from the National Essential Drugs List was $47.68 \%$, which is lower than the WHO standard value $(100 \%) .{ }^{18}$ Only $16.48 \%$ of FDCs were from the National Essential Drugs List.

\section{CONCLUSION}

The present study has reported that most commonly prescribed antimicrobials were quinolones followed by macrolides and $\beta$-lactams. The FDCs of antimicrobials was $32.38 \%$. The rational use of antimicrobial agents is one of the important factors to control the antimicrobial resistance, adverse drug events and health care cost. Recommendations to change the on going prescribing practices should be based on the Standard Treatment Guidelines, EDL and Antibiotic policy or by following the information, education, and communication (IEC) interventions.

\section{Limitations of study}

This study was conducted only in a single department with a limited period of time and sample size. The 
rationality of antimicrobial prescriptions was not checked in this study.

\section{ACKNOWLEDGEMENT}

Authors are thankful to the study participants for giving consent to perform this study.

Funding: No funding sources

Conflict of interest: None declared

Ethical approval: The study was approved by the Institutional Ethics Committee

\section{REFERENCES}

1. WHO. Introduction to drug utilization research/WHO International Working Group for Drug Statistics Methodology, WHO Collaborating Centre for Drug Statistics Methodology, WHO Collaborating Centre for Drug Utilization Research and Clinical Pharmacological Services 2003.

2. Cars O, Mositad S, Melander. A. Variation in antibiotic use in the European Union. Lancet. 2001;357:1851-3.

3. Wise R, Hart T, Cars O. Antimicrobial resistance. Is a major threat to public health. BMJ. 1998;317:60910 .

4. Gold HS, Moellering RC. Antimicrobial drug resistance. New England Journal of Medicine. 1996;335:1445-53.

5. Kakkilaya BS. Rational use of antibiotics. Available from: medicine.org/antibiotics.htm.

6. Rosdahl VT, Pedersen KB. The Copenhagen Recommendations. Report from the Invitational EU Conference on the Microbial Threat. Copenhagen, Denmark 9-10 September 1998. Available from: http://soapimg.icecube.snowfall.se/strama/ Kopenhamnsmotet_1998.pdf.

7. Howell L. Global Risks: An Initiative of the Risk Response Network. Geneva, World Economic Forum, 2013.

8. Kaplan W, Laing R. Priority Medicines for Europe and the World 2004. Available from: http://apps. who.int/iris/bitstream/10665/68769/1/WHO_ EDM_PAR_2004.7.pdf.
9. Cizman M. The use and resistance to antibiotics in the community. Int J Microb Agents. 2003;21:297307.

10. Van Boeckel TP, Gandra S, Ashok A, Caudron Q, Grenfell BT, Levin SA, et al. Global antibiotic consumption 2000 to 2010: an analysis of national pharmaceutical sales data. Lancet Infect Dis. 2014 Aug;14(8):742-50.

11. Finch RG. Antibiotic resistance: a view from the prescriber. Nat Rev Micro. 2004;2(12):989-94.

12. Soumerai SB. Factors influencing prescribing. Aust J Hosp Pharm. 1988;18:9-16.

13. Krishnaswamy K, Dinesh Kumar B, Radhaiah G. A drug survey precepts and practices. Eur J clinpharmacol. 1985;29:363-70.

14. Khan FA, Singh VK, Sharma S, Singh P. Prospective Study on the Antimicrobial Usage in the Medicine Department of a Tertiary Care Teaching Hospital. JCDR. 2013;7(7):1343-46.

15. Selvaraj R. Prospective assessment of antimicrobial prescribing pattern at a tertiary care hospital. Al Ameen J Med Sci. 2015;8(4):276-80.

16. Admane PD, Hiware SK, Mahatme MS, Dudhgaonkar SD, Deshmukh SN, Mahajan MM. Prescription pattern of antimicrobials in tertiary care hospital in central India. Int J of Pharmacol Research. 2015;5(2).

17. Lalan BK, Hiray RS, Ghongane BB. Drug prescription pattern of outpatients in a tertiary care teaching hospital in Maharashtra. Int $\mathbf{J}$ Pharm Bio Sci. 2012 July;3(3):225-9.

18. Isah AO, Ross-Degnan D, Quick J, Laing R, Mabadeje AFB. The development of standard values for the WHO drug use prescribing indicators. ICUM/EDM/WHO.

http://archives.who.int/prduc2004/rducd/ICIUM_Post ers/1a2_txt.htm.

Cite this article as: Hussain $\mathrm{S}$, Sawlani KK, Yadav SS, Khattri S. A prospective assessment of antimicrobial agents utilization pattern in a tertiary care hospital. Int J Basic Clin Pharmacol 2017;6:1459. 